\title{
A privatização do setor postal brasileiro: argumentos favoráveis e contrários
}

A Empresa estatal Brasileira de Correios e Telégrafos, presente em todos os municípios do país, passa por dificuldades por conta de déficits, ineficiência na prestação de serviços e escândalos sobre corrupção e, por isso, tem-se discutido sobre a possibilidade de privatizá-la. Diante disso, o presente estudo, visa, a partir de uma revisão bibliográfica sistematizada, organizar os argumentos favoráveis e contrários à privatização dos serviços postais brasileiros, utilizando-se a análise de conteúdo. Dos 11 (onze) artigos que responderam de forma satisfatória ao problema de pesquisa observou-se, como argumentos favoráveis à privatização: a diminuição do tráfego postal, o déficit financeiro, o fomento à concorrência com abertura para o mercado internacional com melhorias nos produtos e serviços, greves constantes e exemplos positivos de outras privatizações. Já os autores que se posicionam contra a privatização dos Correio internacional com melhorias nos produtos e serviços, greves constantes e exemplos positivos de outras privatizações. Já os autores que se posicionam contra a privatização dos Correios nacional, haverá redução de postos de trabalho, o monopólio é assegurado por normas jurídicas constitucionais, a privatização não gera diminuição do déficit público, há relevância cultura e histórica em manter o monopólio e houve experiências de outros países em que foi possível notar que nenhum país com dimensões parecidas com as do Brasil optou por privatizar totalmente seus serviços postais, apenas países pequenos o fizeram. Após a análise das categorias, concluiu-se que a privatização não é a melhor opção para o setor postal, mas a abertura de seu capital é uma opção a ser considerada para melhorar seus processos e alavancar seus resultados, mantendo o acesso universal aos serviços de logística oferecidos pelos Correios, sobretudo para as are

Palavras-chave: Desestatização; Mercado Postal; Empresa Pública; Setor Privado.

\section{Privatization of the Brazilian postal sector: favorable and contrary arguments}

\begin{abstract}
The state Brazilian Post and Telegraph Company (ECT), present in all cities in the country, goes through difficulties due to deficits, inefficiency in the provision of services and corruption scandals. Because of that, it has been considered and discussed the possibility of privatize this company. Therefore, this study aims, based on a systematic bibliographic review, to organize the arguments for and against the privatization of Brazilian postal services, using content analysis. Of the 11 (eleven) articles that responded satisfactorily to the research problem, the following arguments were favorable for privatization: the decrease in postal traffic, the financial deficit, the promotion of competition with opening to the international market with

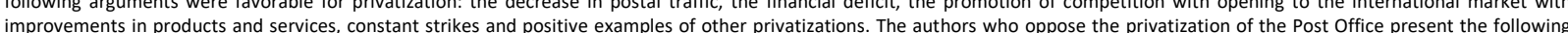
improvements in products and services, constant strikes and positive examples of other privatizations. The authors who oppose the privatization of the Post Office present the following
arguments: the postal monopoly subsidizes the cost of the service in unprofitable areas, the company is profitable, the ECT allows the control of national security operations, there will be a
reduction in posts work, the monopoly is ensured by constitutional legal norms, privatization does not reduce the public deficit, there is cultural and historical relevance in maintaining the reduction in posts work, the monopoly is ensured by constitutional legal norms, privatization does not reduce the public deficit, there is cultural and historical relevance in maintaining the monopoly and there were experiences from other countries in which it was possible to notice that no country with dimensions similar to those of Brazil chose by totally privatizing their postal services, only small countries have done so. After analyzing the categories, it was concluded that privatization is not the best option for the postal sector, but opening the ECT to the stock market is an option to consider, because it could improve its processes and leverage its results while maintaining universal access to the logistics services offered by the Post Office, especially for the most deprived areas.
\end{abstract}

Keywords: Privatization; Postal Market; Public Company; Private Sector.

Topic: Gestão Pública

Reviewed anonymously in the process of blind peer.

Luciana Heloiza Pessoa (id

Universidade Federal de Viçosa, Brasil

http://lattes.cnpq.br/8362080509675735

http://orcid.org/0000-0002-3055-7171

lucianahepessoa@gmail.com

Diego de Sousa Bernardes (iD

Universidade Federal de Viçosa, Brasil

http://lattes.cnpq.br/0503557935116983

http://orcid.org/0000-0002-4329-4665

diego.s.bernardes@ufv.br

Fábio André Teixeira (iD)

Universidade Federal de Viçosa, Brasil

http://lattes.cnpq.br/2311130632500023

http://orcid.org/0000-0003-3527-723X

fateixeira@ufv.br
Received: 04/04/2021

Approved: 06/06/2021
João Alfredo Costa de Campos Melo Júnior (ii)

Universidade Federal de Viçosa, Brasil

http://lattes.cnpq.br/0629454650685817

http://orcid.org/0000-0001-9671-1066

joao.melo@ufv.br

Carlos Eduardo Artiaga Paula

Universidade Federal de Viçosa, Brasil

http://lattes.cnpq.br/3708562405604246

http://orcid.org/0000-0001-6927-9239

carlosartiaga@ufv.br
Referencing this:

PESSOA, L. H.; BERNARDES, D. S.; TEIXEIRA, F. A.; MELO JÚNIOR, J. A. C. C.; PAULA, C. E. A.. A privatização do setor postal brasileiro: argumentos favoráveis e contrários. Revista Brasileira de Administração Científica, v.12, n.2, p.198-211, 2021. DOI: http://doi.org/10.6008/CBPC2179-684X.2021.002.0016 


\section{INTRODUÇÃO}

A Empresa Brasileira de Correios e Telégrafos - ECT, criada através do Decreto-Lei no 509/69, (BRASIL, 1969), visa executar os serviços postais em todo o território nacional. É o único órgão público presente em todos os municípios brasileiros e, muitas vezes, o único órgão federal em várias cidades do interior do país (CARMO, 2015).

A ECT oferece serviços de coleta, envio e entrega de cartas, encomendas e telegramas em todo o território nacional e remessa para o exterior, serviço de inscrição, regularização e alteração de CPF (Cadastro de Pessoa Física), consulta em cadastro de proteção ao crédito, certificado digital, entrada de documentação para recebimento do seguro DPVAT (Danos Pessoais por Veículos Automotores Terrestres), venda de chips de telefonia celular, recarga e portabilidade, logística reversa, comercialização de produtos financeiros, venda de embalagens, produtos de filatelia, certificado digital, Sedex (Serviço de Encomenda Expressa Nacional), PAC (Prático, Acessível e Confiável) selos, serviços financeiros entre outros (ROSA, 2018; AGUIAR, 2018).

Contudo, a partir de 2005, os Correios vêm enfrentando alguns percalços, como má administração, crise financeira agravada pelo avanço da tecnologia e diminuição da correspondência via postal (GASPAROTTO, 2018). A esses, acresce-se escândalos de corrupção, como o noticiado em maio de 2005 em que um funcionário foi flagrado no ato de receber propina de empresários interessados em participar de processos licitatórios (MEDEIROS, 2014). Outro escândalo consistiu no rombo no fundo de pensão dos funcionários - o Postalis - em torno de R\$ 1,2 bilhão, que foi arcado por funcionários ativos e inativos por meio de contribuições extras ao fundo (SILVA, 2018). Devido a esses fatos, começou-se a questionar uma possível privatização ECT.

Nesse contexto, o presente estudo visa identificar os argumentos favoráveis e contrários à possível privatização da ECT e, em seguida, analisar se a privatização manteria os Correios competitivo no mercado e atenderia as necessidades da sociedade brasileira. Esse estudo também é relevante para organizar o conhecimento, disposto da literatura, acerca dos benefícios e prejuízos na privatização da ECT e, desta forma, obter uma visão mais ampla do objeto de estudo.

\section{REVISÃO TEÓRICA}

O presente tópico visa expor os conceitos elementares para esse estudo que são a ECT e também a privatização.

\section{Empresa Brasileira de Correios e Telégrafos}

A ECT é uma empresa pública de direito privado com capital exclusivamente estatal. Criada em 1969 a partir do Decreto-Lei № 509 que transformou o Departamento de Correios e Telégrafos em empresa pública, possui sede em Brasília e é controlada pela União. Por se tratar de uma instituição pública, os Correios são regidos pelo Decreto-Lei no 509/69 e também pela Lei no 6.538/78 a qual regula toda a atividade 
postal, além de portarias, resoluções, estatutos, instruções e outros atos normativos. Essa mesma norma jurídica também afirma que o regime de contratação de seus empregados é a CLT (Consolidação das Leis do Trabalho) (BRASIL, 1969).

A Lei no 6.538/78 também regula todo o serviço postal brasileiro e enumera as atividades que são exploradas pela União em regime de monopólio, como a fabricação e emissão de selos, os serviços de carta, cartão postal e correspondência agrupada. Essa mesma lei traz um rol de itens que não são aceitos e nem entregues pelos Correios, entre os quais estão: planta viva, animal morto, substâncias explosivas, inflamáveis, substâncias de uso proibido, entre outros (BRASIL, 1978).

Financeiramente, a ECT, até o final da década de 90, obteve uma série de resultados positivos. Em 2010 e 2011, seu lucro ficou na casa de R\$ 800 milhões, alcançando seu ápice em 2012, quando atingiu R\$ 1,11 bilhão. Em 2013, a empresa apresentou prejuízo de R\$ 313 milhões. Os resultados negativos continuaram ao longo dos próximos 3 anos e após esse período os Correios voltaram a apresentar resultados financeiros positivos. Em 2017, o lucro da ECT foi de R\$ 667 milhões; em 2018, foi de R\$ 161 milhões e, em 2019, R\$ 102 milhões. Ressalta-se que grande parte dos resultados negativos apresentados pela ECT deve-se aos inúmeros repasses para a União na ordem de milhões de reais no período de 2002 a 2014, como pode ser observado em suas demonstrações financeiras, além dos escândalos de corrupção, conforme já mencionado.

Uma das justificativas da recuperação econômica da ECT é o investimento em tecnologia. O uso de smartphones permite a inserção de informação no SRO (Sistema de Rastreamento de Objetos) em tempo real durante a entrega. Na e-carta, o remetente envia a sua mensagem por meio eletrônico e os Correios se encarregam do restante do processo: impressão, envelopamento e entrega. O uso de softwares, como o SIGEP (Sistema de Gerenciamento de Postagem), permite ao cliente do comércio eletrônico a impressão da etiqueta de postagem tanto em sua residência quanto em sua empresa, locais onde os Correios realizam a coleta do objeto para que não haja necessidade de o cliente comparecer à agência. Além disso, a criação da Universidade Corporativa Correios permite aos funcionários realizarem diversos treinamentos por meio virtual em sua própria cidade (VENCESLAU, 2017).

Todavia, mesmo com as melhorias promovidas e os lucros apresentados, o debate sobre a privatização da ECT intensificou-se após a empresa ser incluída no Programa Parcerias de Investimento (PPI) que busca ampliar e fortalecer a interação do Estado com o setor privado através de medidas de desestatização (BRASIL, 2016). Os Correios foram incluídos nesse programa através do Decreto no 10.066/2019 que visa realizar estudos e avaliação de parcerias com a iniciativa privada para alcançar ganhos de eficiência e sustentabilidade financeira para a empresa.

\section{Privatização}

Privatização ou desestatização é o processo de venda ou de transferência do controle acionário de empresas ou instituições públicas a particulares por meio de licitação com o objetivo reduzir o papel do Estado na economia, transferindo a particulares a execução de determinado serviço. Neste contexto, ativo e 
passivos são transferidos para o setor privado, recebendo estímulos ao seu desenvolvimento e capitalização no mercado financeiro.

O termo privatização abarca a desregulação, a desmonopolização, a venda de ações de empresas estatais, a concessão de serviços públicos e o contracting out, que abarca convênios e contratos de obras e prestação de serviços públicos (DI PIETRO, 2003); tudo no fito de fazer com que a atividade econômica deixe de ser controlada pelo Estado e passe ao setor privado (BRITTO, 1995). Em 1990, foi instituído o Programa Nacional de Desestatização (PND), por meio da Lei no 8.031/90, que tinha como meta central transferir atividades exercidas pelo Estado para o setor privado e reduzir a dívida pública. O PND possuía uma peculiaridade: as empresas adquiridas no processo de privatização poderiam ser compradas por meio de títulos vencidos da dívida pública, que eram aceitos pelo seu valor de face (valor a ser resgatado ao final da aplicação), mas negociados no mercado com desvalorizações consideráveis, o que fez com que se ficassem conhecidos como de "moedas podres" (BARBOSA, 2010).

As empresas que podem ser desestatizadas são as controladas pelo Estado ou que passaram a seu controle direto ou indireto; serviços públicos que foram objetos de concessão, permissão ou autorização, instituições financeiras e bens imóveis pertencentes ao Estado. Entre os objetivos do PND, desenvolvido pela União, estão a estruturação econômica do setor público, a retomada de investimentos nas empresas privatizadas e a diminuição da dívida pública líquida (BRASIL, 1997).

Embora tenham iniciado na década de 80, as privatizações ganharam destaque a partir da década de 90, quando começaram a ser privatizadas as empresas do setor de serviços públicos, embasados em argumentos neoliberais, como os que defendiam que o Estado não deveria executar atividades do setor privado e concentrar suas ações em áreas consideradas prioritárias como educação, segurança e regulação. Defendia-se também que a privatização estimularia o investimento produtivo, diminuiria a concentração do mercado de ações e criaria um ambiente mais competitivo, com o fim dos monopólios públicos.

Pinheiro et al. (2000), ao tratarem dos antecedentes macroeconômicos e da estrutura institucional da privatização no Brasil, enumeraram como primeiro aspecto de estímulo à privatização no Brasil o fraco desempenho econômico das Empresas Estatais (EEs). E ressalta que o movimento de apoio à privatizou aumentou para 'restringir os gastos público e porque a tentativa malograda de utilizar as EEs como instrumento de política macroeconômica nos anos 80 levou a uma profunda deterioração da qualidade dos serviços oferecidos por essa companhia'.

$\mathrm{Na}$ década de 90, a privatização sinalizou o compromisso de reduzir a participação do Estado na economia, sobretudo porque uma inflação controlada ampliava a possibilidade dos governos de adotar um programa ambicioso de redução do Estado. Ademais, a privatização se tornou essencial para sustentar o Plano Real (aumentou a captação de Investimentos Externos Diretos (IED) que ajudou a financiar o elevado déficit em transações correntes e a sanar parte da dívida pública impedindo seu crescimento). Quando as privatizações foram estendidas às empresas de serviço público, passou-se a gerar receitas muito superiores, à ordem de US\$ 68,9 bilhões em 1996, expressivamente superior às privatizações de 1991-5 que geraram apenas 2,7 bilhões (PINHEIRO et al., 2000). 
Portanto, o maior volume de recursos provenientes das privatizações aconteceu na década de 90 a partir de estratégias, como concessões, licenciamentos ambientais, arrendamentos de terminais, megaleilões, vendas de ativos e subsidiárias, Parcerias Públicos Privadas (PPPs) e venda de participação.

A primeira grande empresa estatal privatizada no Brasil foi a Usiminas, uma siderúrgica localizada em Ipatinga no Estado de Minas Gerais (GIMENEZ, 2013). Contudo, o marco de privatizações foi a venda da Telebrás - Brasil Comunicações S.A e também a privatização da Companhia Vale do Rio Doce, empresas de setores estratégicos no país (TAVARES, 2019). De 2003 a 2013, as privatizações se concentraram basicamente em rodovias federais, portos, aeroportos e pequenos bancos estaduais (PEREIRA, 2019).

Uma das privatizações que mais gerou polêmica foi a da Companhia Vale do Rio Doce (CVRD), pois se tratava da maior mineradora do mundo. Tal situação gerou protestos seja por parte de funcionários da companhia que temiam perder seus empregos, seja por grupos políticos que eram contra a venda da estatal e também por parte da população. Houve passeatas nas ruas do Rio de Janeiro onde a empresa mantinha o seu principal escritório e onde suas ações seriam negociadas em bolsa. Houve protestos contra a sua venda em cidades onde ela atuava e também ações na justiça impetradas por entidades sindicais e advogados que se opunham à venda da estatal (ALMEIDA, 2009). Em 1997, a CVRD foi vendida a grupos privados por um montante muito abaixo do valor de seu patrimônio (SOUSA, 2008). Dez anos após a venda da CVRD ao setor privado, seu valor de mercado aumentou substancialmente passando de US\$ 10 bilhões para US\$ 97 bilhões e o número de empregados aumentou para 52 mil (ARÊAS, 2013).

Outra privatização de destaque foi a Telebrás, a partir da quebra do monopólio do serviço de telefonia em 1995 e posterior instituição da agência reguladora do setor, a Anatel (Agência Nacional de Telefonia). A privatização completa do setor ocorreu em julho de 1998 através de 12 leilões na Bolsa do Rio de Janeiro em que foi vendido parte do setor de telecomunicações brasileiro que envolvia telefonia fixa e celular. Após a privatização, houve redução de postos de trabalho com vistas a maximizar o lucro dos operadores (COSTA NETO, 2002). A privatização do sistema Telebrás trouxe avanços significativos com aumento de qualidade e a entrada de novos investidores (PEREIRA, 2019).

A privatização demonstrou-se, portanto, uma relevante ferramenta de gestão pública de tal forma que os Governos Lula, Dilma, Temer e Bolsonaro tiveram estas ações em suas agendas administrativas por considerarem as privatizações como essenciais para a retomada da economia brasileira 'para aumentar o nível de investimentos no país e também para liberar recursos públicos, uma vez que União e estados passam por uma gigantesca crise financeira'.

A crescente dívida pública brasileira (a dívida líquida do setor público atingiu 60,2\% do PIB e a dívida bruta atingiu 86,5\% do PIB em 2019) tornou a situação fiscal quase insustentável e a necessidade de recursos é cada vez mais proeminente, sobretudo no contexto da pandemia de 2020. Assim, aceleram-se as propostas e os diversos projetos passam a ser considerados essenciais para estimular o crescimento econômico, gerar emprego e sanar as contas públicas. Mudam-se os anos, mas a justificativa de que as privatizações são necessárias para equilibrar o déficit fiscal, gerar investimentos em infraestrutura e diminuir a participação do Estado na economia, permanece. De acordo com o quadro 1 há 119 projetos federais de privatização em 
andamento em 2020.

Quadro 1: Projetos federais de privatização em andamento no ano de 2020.

\begin{tabular}{|c|c|}
\hline Ferrovias :11 & Rodovias : 17 \\
\hline - 5 renovações & -9 concessões \\
\hline - 2 concessões & - 6 licenciamentos ambientais \\
\hline - 4 investimentos cruzados & - 2 estudos \\
\hline Portos :20 & Aeroportos: 22 \\
\hline - 14 arrendamentos de terminais & 22 concessões agrupadas em 3 blocos (Sul, Norte e Central) \\
\hline \multicolumn{2}{|l|}{ - 2 autorizações para investimentos } \\
\hline - 1 hidrovia & Abastecimento: 2 \\
\hline - 3 privatizações (porto de Santos, São Sebastião e Vitória) & 2 privatizações: Ceagesp e CeasaMinas \\
\hline Energia: 21 & Óleo e Gás: 3 \\
\hline - 12 lotes de linhas de transmissão & - 1 megaleilão da cessão onerosa \\
\hline - 5 licenciamentos ambientais & - 6a rodada de partilha \\
\hline - 1 leilão de energia nova & - 16ạ rodada de concessão \\
\hline \multicolumn{2}{|l|}{ - 1 concessão } \\
\hline - 1 parceria para conclusão de Angra 3 & Mineração: 5 \\
\hline - 1 privatização (eletrobrás) & - 5 concessões de exploração de direitos minerários. \\
\hline Economia e tecnologia: 8 & - Parques nacionais: 3 \\
\hline $\begin{array}{l}\text { - } 6 \text { privatizações (Casa da Moeda, Serpro, Dataprev, ABGF, } \\
\text { Emgea e Ceitec) }\end{array}$ & - 3 concessões (Lençóis Maranhenses, Jericoacoara e Iguaçu) \\
\hline - 1 Concessão (Lotex) & Defesa e Segurança: 2 \\
\hline - 1 venda de participação (ações da União no BB) & - 2 PPPs (Comaer e Comunicações policiais) \\
\hline - Comunicações : 2 & Desenvolvimento Regional: 3 \\
\hline \multirow[t]{2}{*}{2 privatizações (Correios e Telebrás) } & - 2 privatizações (CBTU e Trensurb) \\
\hline & $\begin{array}{l}\text { - } 1 \text { parceria para a conclusão de obras (Integração do Rio São } \\
\text { Francisco) }\end{array}$ \\
\hline
\end{tabular}

Contudo, o caso da privatização dos Correios é considerado mais complexo e pode levar mais tempo, porque, além da atualização de leis, deve-se fazer alterações na Constituição Federal, o que é deveras mais difícil quando comparado às demais espécies legislativas (BRASIL, 1988).

\section{METODOLOGIA}

O presente artigo trata-se de uma revisão bibliográfica sistematizada e para sua fundamentação foram coletados artigos científicos que versam sobre a temática da privatização da ECT no Google Acadêmico, Scielo e Spell. As buscas foram desenvolvidas a partir da seguinte fórmula de busca: (privatização OR desestatização) AND (correios OR serviços postais OR Empresa Brasileira de Correios e Telégrafos OR empresa estatal). Limitou-se a análise aos 100 primeiros resultados por base de dados em razão do elevado número de resultados obtidos.

Considerou-se apenas estudos em língua portuguesa delimitados e artigos publicados entre janeiro de 2000 a março de 2020. A partir dos referidos critérios, obteve-se, em um primeiro momento, 879 (oitocentos e setenta e nove) artigos. Após a leitura dos resumos, foram pré-selecionados 61 (sessenta e um), os quais foram lidos por completo para se chegar a 11 (onze) artigos que atendiam ao objetivo de pesquisa e que se encontram descritos no quadro 2 abaixo: 
Quadro 2: Artigos base do estudo.

\begin{tabular}{|c|c|c|}
\hline Título & Autor & $\begin{array}{l}\text { Ano de } \\
\text { publicação }\end{array}$ \\
\hline $\begin{array}{l}\text { A natureza jurídica da Empresa Brasileira de Correios e Telégrafos (ECT): uma empresa } \\
\text { pública federal eficiente? }\end{array}$ & $\begin{array}{l}\text { Alexandra Rocha } \\
\text { Roedel }\end{array}$ & 2019 \\
\hline $\begin{array}{l}\text { Análise de cenários para a indústria postal brasileira: um estudo sobre a adequação da } \\
\text { distribuição domiciliária às tendências do mercado }\end{array}$ & $\begin{array}{l}\text { Fernanda Rocha de } \\
\text { Aguiar }\end{array}$ & 2018 \\
\hline Como privatizar os Correios: uma oportunidade como ponte para solução & $\begin{array}{l}\text { Francisco Martins } \\
\text { Loenert }\end{array}$ & 2018 \\
\hline Monopólio postal: sua relevância e as transformações do sistema postal & $\begin{array}{l}\text { Gustavo Fonseca e } \\
\text { Silva }\end{array}$ & 2018 \\
\hline $\begin{array}{l}\text { Os } 350 \text { anos da Empresa Brasileira de Correios e Telégrafos: o desafio de se reinventar } \\
\text { como empresa pública e atuar em novos mercados e serviços }\end{array}$ & $\begin{array}{l}\text { Terezinha de Fátima } \\
\text { Nunes do Carmo }\end{array}$ & 2015 \\
\hline $\begin{array}{l}\text { O sistema postal brasileiro em transformação: propostas e mudanças na regulação do } \\
\text { mercado e na reestruturação do modelo organizacional da Empresa Brasileira de } \\
\text { Correios e Telégrafos (1994-2011) }\end{array}$ & $\begin{array}{l}\text { Tadeu } \quad \text { Gomes } \\
\text { Teixeira }\end{array}$ & 2014 \\
\hline $\begin{array}{l}\text { Processo de privatização das empresas estatais brasileiras: uma análise a respeito do } \\
\text { direito ao emprego pelos empregados públicos }\end{array}$ & $\begin{array}{l}\text { Ana Letícia Vilar } \\
\text { Dantas }\end{array}$ & 2019 \\
\hline Constitucionalidade do monopólio da Empresa Brasileira de Correios e Telégrafos & $\begin{array}{l}\text { Mariana Aparecida } \\
\text { Dias Borges }\end{array}$ & 2019 \\
\hline $\begin{array}{l}\text { Tendências do setor postal no cenário internacional: liberalização, regulação do mercado } \\
\text { e reestruturação organizacional }\end{array}$ & $\begin{array}{l}\text { Tadeu } \\
\text { Teixeira }\end{array}$ & 2016 \\
\hline Um modelo de privatização completa via leilão para os Correios & Marcelo de Arruda & 2018 \\
\hline Como Privatizar os Correios à luz dos pensadores liberais & $\begin{array}{l}\text { Daniel Bastos } \\
\text { Gasparotto }\end{array}$ & 2018 \\
\hline
\end{tabular}

Em seguida, os 11 artigos selecionados foram lidos na íntegra. Suas informações foram compiladas e, em observância à análise de conteúdo de Bardin (2011), os dados coletados foram organizados em duas categorias: os argumentos favoráveis e os contrários à privatização. Cada uma dessas categorias gerou subcategorias que se encontram descritas no tópico 4 (resultados e discussões) e encontram-se sintetizados nos quadros 3 e 4 abaixo. O referido esforço metodológico culminou no presente artigo.

\section{RESULTADOS E DISCUSSÃO}

Dos 11 (onze) artigos selecionados, alguns se manifestaram contrários, outros favoráveis e outros não apresentaram um posicionamento bem definido quanto à privatização da ECT. Esses se limitaram a apresentar possíveis consequências da privatização da instituição, como o aumento da eficiência da empresa e o não atendimento a todas as cidades brasileiras. Apresentaram argumentos favoráveis e contrários à privatização e, por isso, foram incluídos nesse estudo. A figura 1 sintetiza o posicionamento dos autores face à possível privatização da ECT.

\begin{tabular}{|c|c|c|}
\hline Contra a privatização & $\underline{\text { Indefinidos }}$ & A favor da privatização \\
\hline & Carmo (2015) & Arruda (2018) \\
\hline Aguiar (2018) & Dantas (2019) & Borges (2019) \\
\hline Silva (2018) & Teixeira (2014) & Gasparotto (2018) \\
\hline
\end{tabular}

Figura 1: Posicionamento dos artigos base frente a uma possível privatização da ECT

Dos 11 (onze) artigos estudados, 5 (cinco) se posicionaram a favor de uma possível privatização dos Correios, cujos argumentos foram organizados nas categorias, dispostas no quadro 3. 
Quadro 3: Argumentos favoráveis à privatização.

\begin{tabular}{|l|l|l|}
\hline Argumento favorável à privatização & Autores que o citaram & $\begin{array}{l}\text { Quantidade de artigos que } \\
\text { apresentaram o argumento }\end{array}$ \\
\hline Diminuição do tráfego postal devido à tecnologia & $\begin{array}{l}\text { Roedel (2019); Silva (2018); Carmo } \\
\text { (2015); Teixeira (2014; 2016) }\end{array}$ & 5 \\
\hline Déficit financeiro & $\begin{array}{l}\text { Roedel (2019); Borges (2019); } \\
\text { Gasparotto (2018); Arruda (2018); } \\
\text { Teixeira (2014) }\end{array}$ & 5 \\
\hline $\begin{array}{l}\text { Fomentar a concorrência com a abertura para o } \\
\text { mercado internacional e melhorias nos produtos e } \\
\text { serviços }\end{array}$ & $\begin{array}{l}\text { Roedel (2019); Loenert (2018); Borges } \\
\text { (2019); }\end{array}$ & 3 \\
\hline Greves constantes & Aguiar (2018); Gasparotto (2018); & 2 \\
\hline Exemplos positivos de outras privatizações & Dantas (2019); Arruda (2018); & 2 \\
\hline
\end{tabular}

Na categoria "diminuição do tráfego postal devido à tecnologia", sustenta-se que o volume de cartas e telegramas vem diminuindo gradativamente devido ao avanço tecnológico e a abertura do mercado postal propiciaria o desenvolvimento de novas tecnologias (AGUIAR, 2018). A ECT é uma empresa bastante popular e inclusiva, mas que não está atualizada tecnologicamente, como o mercado privado (ROEDEL, 2019).

Já na categoria 'déficit financeiro', os resultados negativos acumulados no período de 2013 a 2016 na ordem de $R \$ 3,9$ bilhões também são argumentos apresentados para a venda dos Correios a operadores privados. No entanto, grande parte desse déficit deve-se aos inúmeros repasses da empresa para a União que, no período de 2000 a 2010, importou em 1,9 bilhões.

No que tange ao "fomento da concorrência", a exclusividade da prestação do serviço postal pela União seria um empecilho à qualidade do serviço prestado pelos Correios. O monopólio estatal atrapalha o fornecimento de um serviço de qualidade à população com custo alto e pouca eficiência (BORGES, 2019). Por isso, abrir o mercado postal para que novas empresas atuem no setor e diminuir a atuação do Estado permitiria novos investimentos, ampliaria a concorrência e reduziria preços ao consumidor (BORGES, 2019).

Uma opção para melhorar a qualidade dos serviços seria, inclusive, a abertura do mercado postal para empresas estrangeiras, como a DHL (Dalsey, Hillblom and Lynn), a UPS (United Parcel Service) e a TNT (Thomas Nationwide Transport), além da própria FedEx (Federal Express), embora iniba a criação de empresas postais nacionais já que as internacionais possuem maior capital (ROEDEL, 2019). Desta forma, a privatização dos Correios possibilitaria investimentos de empresas brasileiras no setor postal, o que ampliaria a concorrência e reduziria drasticamente o preço dos serviços (BORGES, 2019).

A geração de concorrência traria benefícios como queda nos preços, aumento de produtos e serviços e aumento no número de empregados (AGUIAR, 2018), assim como ocorreu no serviço de telefonia. Roedel (2019) contradiz o argumento dos defensores do monopólio do serviço postal, ao afirmar que "os Correios se recusam a fazer entregas em lugares perigosos e com restrições geográficas, o que a coloca no mesmo patamar, se não inferior, a qualquer hipotética empresa privada" (ROEDEL, 2019).

A edição de normas regulamentadoras para o setor e a instituição de um órgão responsável pela transição do público para o privado é o caminho a ser percorrido para que a privatização da ECT seja bemsucedida. A criação de uma agência reguladora provisória fomentaria a livre concorrência, editaria normas e resolveria conflitos que viessem a surgir e, assim que o processo de privatização estivesse concluído, a agência deveria ser encerrada (GASPAROTTO, 2018). 
A revogação de algumas normas jurídicas como o art. 21, inciso X da Constituição (BRASIL, 1988) desobrigaria a União da manutenção do serviço postal e haveria a mudança da ECT de empresa pública para sociedade anônima. Desta forma, a oferta pública de ações levantaria capital para o pagamento de dívidas e fortaleceria a empresa (ROEDEL, 2019; GASPAROTTO, 2018). Logo, a privatização geraria mais receita, maior ganho de eficiência e melhor viabilidade de execução além de ser uma alternativa mais realista dentro do contexto da ECT (ARRUDA, 2018).

Quanto à categoria "greves constantes", deve-se, inicialmente, realizar alguns esclarecimentos. Greve é a paralisação do trabalho de forma deliberada com vistas à modificação, conservação ou criação de direito por parte de funcionários. A greve torna público o conflito e alerta para a situação atual, quebra possíveis intransigências e acelera a solução do conflito (ARAÚJO, 2011). A paralisação de parte do efetivo da ECT é o modo que os funcionários e sindicatos acharam para que suas manifestações sejam aceitas após não haver conciliação com a direção da empresa. Contudo, o problema é que as greves dos funcionários dos Correios têm sido recorrentes, ademais, induzem os clientes a buscarem alternativas para a prestação do serviço (AGUIAR, 2018), levando a cáusticos prejuízos à ECT. Por isso, as frequentes greves são um argumento favorável à privatização.

Por fim, o último argumento observado nos artigos coletados, que defendem a privatização dos Correios, são os "exemplos de outras privatizações anteriores" que trouxeram avanços em algumas áreas, como a de telefonia por exemplo. Mas esses avanços vieram acompanhados de evolução tecnológica, que permitiram o sucesso das empresas privadas. A privatização do setor telefonia foi acompanhado da obrigação de universalizar a telefonia por meio dos "orelhões", porém essa disseminação ocorreu através dos telefones celulares (AGUIAR, 2018). Outro exemplo bem-sucedido é o caso da CVRD - Companhia Vale do Rio Doce que ocorreu em 1997, conforme já mencionado

Em oposição aos argumentos a favor da privatização dos Correios, há autores que apoiam a manutenção do monopólio dos serviços postais, conforme demonstra o quadro 4 abaixo:

Quadro 4: Argumentos contrários à privatização.

\begin{tabular}{|l|l|l|}
\hline Argumento contrário à privatização & Autores que o citaram & $\begin{array}{l}\text { Quantidade de artigos que } \\
\text { apresentaram o argumento }\end{array}$ \\
\hline $\begin{array}{l}\text { Monopólio postal subsidia o custo do } \\
\text { serviço em áreas não rentáveis }\end{array}$ & $\begin{array}{l}\text { Roedel (2019); Gasparotto (2018); Teixeira (2014); } \\
\text { Dantas (2019); Borges (2019); Aguiar (2018); Silva } \\
\text { (2018); }\end{array}$ & 7 \\
\hline Custo operacional & Loenert (2018); & 1 \\
\hline $\begin{array}{l}\text { Controle de operações de segurança } \\
\text { nacional }\end{array}$ & Loenert (2018); & 1 \\
\hline Redução de postos de trabalho & $\begin{array}{l}\text { Silva (2018); Carmo (2015); Dantas (2019); Teixeira } \\
\text { (2016); Arruda (2018); }\end{array}$ & 5 \\
\hline $\begin{array}{l}\text { Monopólio assegurado por normas } \\
\text { jurídicas constitucionais }\end{array}$ & Teixeira (2014); Borges (2019); & 2 \\
\hline $\begin{array}{l}\text { A privatização da ECT não gera } \\
\text { diminuição do déficit público }\end{array}$ & Dantas (2019); & 1 \\
\hline A ECT é lucrativa & Dantas (2019); & 1 \\
\hline Relevância cultural e histórica & Borges (2019); & 1 \\
\hline Experiência de outros países & Gasparotto (2018); Teixeira (2016) \\
\hline
\end{tabular}

A primeira categoria "monopólio postal subsidia o custo do serviço em áreas não rentáveis" sustenta, 
em síntese, que o monopólio visa subsidiar o custo dos serviços postais em regiões de baixo retorno financeiro. O serviço postal precisa ser prestado em todas as regiões do país com custos acessíveis, o que nem sempre segue as leis do mercado, ou seja, a privatização da ECT é complexa visto que o mercado postal tem sua base no papel social prestado pelos Correios (AGUIAR, 2018).

O serviço postal precisa ser realizado em todo território nacional, em alguns casos sem seguir a lógica de mercado, causando prejuízos aos negócios. Os Correios estatais prestam o serviço com qualidade neste cenário, o que não ocorre com as empresas postais privadas, pois se não houver lucro não há prestação de serviço. (SILVA, 2018)

Uma possível privatização da ECT poderia resultar em diminuição do número de agências no país e, por consequência, o valor dos serviços postais também sofreria mudanças, pois o monopólio postal possibilita ainda que o custo dos serviços seja abaixo do preço de mercado nessas regiões remotas (TEIXEIRA, 2014), justamente por não buscar o lucro, mas possibilitar o acesso ao serviço postal em todo o território nacional.

Na categoria "custo operacional", explica-se que os serviços dos Correios são onerosos em razão de seus custos elevados, já que "conectar todos os municípios brasileiros em distâncias continentais [...] eleva o custo fixo em infraestrutura suportado pela firma" (LOENERT, 2018). Logo, empresas privadas poderiam não se interessar em prestar o serviço postal em todas as localidades atendidas pela ECT devido ao alto custo envolvido na execução da atividade postal e seu baixo retorno financeiro. Loenert (2018), aponta que:

Quanto maior os custos fixos ou menores os lucros por consumidor, maior será o tamanho do mercado necessário para a entrada de mais um concorrente. Deste modo, entendemos como restrito no que tange as atividades de elevados custos fixos dos Correios.

Logo, a prestação do serviço postal em algumas regiões do país possui um custo muito elevado devido à distância entre algumas localidades e à infraestrutura necessária para a prestação dos serviços, o que o torna desinteressante para a atuação de empresas privadas.

A respeito da categoria "controle de operações de segurança nacional" salienta-se que a privatização dos Correios se torna delicada ao se analisar o termo segurança, visto que há necessidade de uma severa fiscalização do operador logístico para que sua estrutura não seja usada para fins ilegais como o transporte de armas, tráfico de drogas, animais, entre outros (LOENERT, 2018). Logo, manter uma instituição pública facilita sobremaneira a fiscalização e ingerência do Estado, diminui custos de fiscalização e, ainda, ameniza a utilização dos serviços postais para fins ilícitos.

Quanto à "redução dos postos de trabalho", a privatização da ECT levaria a uma diminuição de empregos. Isto porque os funcionários da ECT, que são empregados públicos regidos pela CLT, não possuem a mesma estabilidade dos servidores públicos estatutários (DANTAS, 2019). Logo, uma possível privatização da empresa poderia colocar seus empregos em risco. Essa redução dos postos de trabalho ocorreu em países onde houve a privatização dos serviços postais, como a Alemanha, Áustria, Holanda e Bélgica (TEIXEIRA, 2016).

Teixeira (2016) ao se referir aos postos de trabalho, esclareceu que "a precarização do trabalho é a outra face do processo (trabalho em tempo parcial, pagamento por jornada, etc.), o que tem enfraquecido o poder sindical de negociação". Logo, na perspectiva do trabalhador da ECT, a privatização não é desejável. 
Outro argumento observado neste estudo versa que o monopólio estatal é assegurado por normas jurídicas constitucionais, pois a legislação brasileira assegura a prestação do serviço postal como exclusividade da ECT. Ainda, compete à União manter o serviço postal e o correio aéreo nacional (art. 21, $\mathrm{X}$ e 22, V da CF (BRASIL, 1988)). Em oposição a essa disposição legal, a ABRAED (Associação Brasileira das Empresas de Distribuição) ingressou no STF (Supremo Tribunal Federal) com a ADPF no 46 (Arguição por Descumprimento de Preceito Legal) alegando que o monopólio postal seria inconstitucional (BORGES, 2019), mas a ação foi julgada improcedente, pois o STF entendeu ser o monopólio lícito e em conformidade com a Constituição (BORGES, 2019).

Outra tese contrária à privatização da ECT é que esta não gera uma diminuição no déficit público. Essa categoria se opõe ao argumento de que a venda da estatal acarretaria renda ao Estado, diminuiria as despesas e geraria renda a partir dos tributos recolhidos pelas empresas privadas (ARRUDA, 2018). As experiências brasileiras com a privatização mostram o contrário: a privatização de empresas públicas não teve impacto direto na redução da dívida pública e as receitas advindas desse processo são transitórias. Ademais, não houve investimentos significativos em áreas como saúde, educação e segurança pública (DANTAS, 2019). Nesse sentido, as privatizações ocorridas entre os anos de 1994 a 1998 renderam em torno de R\$ 78 bilhões. Contudo, nesse mesmo período, a dívida pública passou de US\$ 60 bilhões para US\$ 245 bilhões (PEREIRA, 2019).

Em sentido contrário ao argumento do déficit público, a ECT é lucrativa, que é outra categoria deste estudo. Isto porque, apesar de alguns resultados negativos no período de 2013 a 2016, em outros anos os resultados foram positivos. A partir de 2017, em todos os anos a empresa apresentou resultados positivos acima de R\$ 100 milhões. Gasparotto (2018) afirmou que: "os Correios apresentaram lucro líquido nos anos 2011 e 2012 [...]. A situação se repetiu em 2013". Em 2018, a ECT apresentou lucro de R\$ 161,05 milhões (DANTAS, 2019).

Outra categoria mencionada é a de que os Correios possuem uma relevância cultural e histórica no Brasil. Por ser uma empresa de alcance nacional e presente em todos os municípios brasileiros, a ECT contribui para o desenvolvimento econômico e social do país, pois sua capilaridade permite a execução de serviços postais especiais, como aquele prestado nos Jogos Olímpicos de 2016 quando os Correios foram o operador logístico oficial e entregaram mais de 30 milhões de itens, incluindo desde materiais utilizados diretamente nas competições até a bagagem dos próprios atletas (VENCESLAU, 2017). Ainda, faz parte da construção cultural e histórica, pois "o Correio foi - e ainda é - um elemento importante na formação socioespacial brasileira, tendo participado ativamente do processo de integração do território nacional" (VENCESLAU, 2017).

Por fim, a última categoria refere-se às experiências de outros países, observados nos trabalhos de Teixeira (2016) e Gasparotto (2018), que vivenciaram o processo de privatização dos serviços postais. Na União Europeia, a liberalização do setor foi gradual. Na Alemanha, atuam 7 grandes empresas que dominam o mercado (oligopólio); o processo de abertura teve início em 1997 e foi concluído em 2007. No entanto, houve grandes cortes nos postos de trabalhos. 
No Reino Unido, o setor postal saiu do controle estatal para empresas privadas no formato S.A. (sociedade anônima). Em 2006, o mercado foi totalmente aberto à competição com a participação de pequenas empresas locais e também de empresas tradicionais e nota-se que não houve privatização, mas abertura do mercado a novos entrantes. Na Áustria e na Polônia, a maior parte do setor ainda está sob o controle do Estado. Há de se notar o caso especial da Argentina que foi privatizada em 1997 e em 2003 voltou para o controle estatal devido a crises no setor e ineficiência do operador privado. Com a reestatização, houve aumento no número de postos de trabalho com a manutenção do formato S.A. (TEIXEIRA, 2016). No Japão, a privatização teve início em 2003, mas a maior parte das ações pertencem ao governo (GASPAROTTO, 2018).

Nota-se, então, que a grande maioria dos países que optaram pela privatização de seus serviços postais são países pequenos, como os países europeus e o Japão. $O$ único exemplo de privatização que se tem de um país com dimensões parecidas com o Brasil é os Estados Unidos, a maior potência mundial e que mantém parte de seu serviço postal público. No Brasil, há regiões de difícil acesso que são atendidas pela ECT e contam com o serviço da estatal para recebimento de medicamentos, livros didáticos e até urnas eletrônicas em anos eleitorais. Esses serviços precisariam ser garantidos por novos entrantes no mercado no caso de uma possível privatização da ECT (VENCESLAU, 2017).

\section{CONCLUSÕES}

A evolução tecnológica afetou sobremaneira o negócio das empresas postais em todo o mundo. A diminuição do volume de cartas e a disseminação de meios de comunicação digital transformaram o tráfego postal que antes era, em sua maioria, composto por cartas, mas, agora, há o predomínio de encomendas com o comércio eletrônico.

Os Correios detêm apenas o monopólio da entrega de cartas e está presente em todos os municípios do país onde exercem um importante papel social e de integração nacional. Uma possível privatização da Empresa poderia trazer inúmeros prejuízos a populações de lugares mais remotos do país, onde muitas vezes o serviço postal é o único modo de envio e recebimentos de encomendas como medicamentos e livros didáticos e que, por não ser um mercado rentável, não desperta o interesse de operadores privados.

O monopólio postal assegura à ECT a arrecadação de receitas em regiões rentáveis como os grandes centros urbanos, o que propicia condições de atender regiões onde o serviço postal não cobre seus custos de operação sem a necessidade de recorrer a recursos da União. Preserva-se, desse modo, o atendimento a todas as regiões do país e também a sustentabilidade financeira da Empresa. Por isso, os autores desse estudo posicionam-se contrários à privatização da ECT.

Uma possibilidade a se investigar, no intuito de aumentar a competitividade da ECT, é convertê-la em sociedade anônima, com a maior parte do capital público e controle da União, aos moldes do que ocorre com o Banco do Brasil. Essa mudança poderia melhorar seus processos, alavancar seus resultados financeiros e operacionais, sem deixar de atender as necessidades dos moradores de regiões de mais difícil acesso do país e populações mais vulneráveis. Assim, manter-se-ia a sustentabilidade financeira da ECT e também seu 
importante papel social.

\section{REFERÊNCIAS}

AGUIAR, F. R.. Análise de cenários para a indústria postal brasileira: estudo sobre a adequação da distribuição domiciliária às tendências do mercado. Dissertação (Mestrado em Gestão e Negócios) - Universidade do Vale do Rio dos Sinos, Porto Alegre, 2018.

ALMEIDA, M. D.. Neoliberalismo, privatização e desemprego no Brasil (1980-1998). Tese de doutorado. Universidade Estadual de Campinas, 2009.

ARAÚJO, F. D.. Negociação coletiva dos servidores públicos. Belo Horizonte: Forum, 2011.

ARÊAS, J. B.. As privatizações no Brasil dos anos 90. Episteme Transversalis, v.4, n.2, 2017.

ARRUDA, M.. Um Modelo de Privatização Completa Via Leilão para os Correios. MISES: Interdisciplinary Journal of Philosophy, Law and Economics, v.6, n.2, 2018.

BARBOSA, L. M. L. H.. O processo de privatização brasileiro e o seu efeito fiscal na década de 1990 . Monografia (Bacharelado) - Instituto Federal do Rio de Janeiro, Rio de Janeiro, 2010.

BARDIN, L.. Análise de conteúdo. São Paulo: Edições 70, 2011.

BORGES, M. A. D.. Constitucionalidade do monopólio da Empresa Brasileira de Correios e Telégrafos. Monografia (Bacharelado em Direito) - Centro Universitário Toledo, Araçatuba, 2019.

BRASIL. Constituição de 1988. Constituição da República Federativa do Brasil: promulgada em 5 de outubro de 1988. Brasília: DOU, 1988.

BRASIL. Decreto-Lei n. 509, de 20 de março de 1969. Dispõe sobre a transformação do Departamento dos Correios e Telégrafos em empresa pública, e dá outras providências. Brasília. DOU, 1969.

BRASIL. Estatuto Social dos Correios. Em observância à Lei 13.303/2016 e ao Decreto 8.945/2016, apresenta-se o Estatuto Social dos Correios que define o objeto social, as regras gerais dos órgãos estatutários, capital social e outros temas. Brasília: DOU, 2016.

BRASIL. Lei n. 9.491, de 09 de setembro de 1997. Altera procedimentos relativos ao Programa Nacional de Desestatização, revoga a Lei n 8.031, de 12 de abril de 1990, e dá outras providências. Brasília: DOU, 1997.

BRASIL. Lei n. 6.538, de 22 de junho de 1978. Dispõe sobre os Serviços Postais. Brasília: DOU, 1978.

BRITTO, C. A.. A privatização das empresas estatais à luz da Constituição. Revista de Direito Público, v.12, n.1, p.99-119, 1995. DOI: http://dx.doi.org/10.11606/issn.23190558.v2n1p99-119
CARMO, T. F. N.. Os 350 anos da Empresa Brasileira de Correios e Telégrafos: o desafio de se reinventar como empresa pública e atuar em novos mercados e serviços. Monografia (Especialização em Gestão Pública) Universidade Federal do Rio Grande do Sul, Porto Alegre, 2015.

COSTA NETO, D.. O quadro das telecomunicações brasileiras na década de noventa do século XX: transformações provocadas pelo programa de privatização. Monografia (Bacharelado) - Universidade Federal da Bahia, Salvador, 2002.

DANTAS, A. L. V.. Processo de privatização das empresas estatais brasileiras: uma análise a respeito do direito ao emprego pelos empregados públicos. Monografia (Bacharelado em Direito) - Universidade Federal de Campina Grande, Sousa, 2019.

DI PIETRO, M. S. Z.. Parcerias na Administração Pública: concessão, permissão, franquia, terceirização e outras formas. 4 ed. São Paulo: Atlas, 2003.

GASPAROTTO, D. B.. Como Privatizar os Correios à luz dos pensadores liberais. MISES: Interdisciplinary Journal of Philosophy, Law and Economics, v.6, n.2, 2018.

GIMENEZ, A. R. P. A.. Privatizações no governo FHC e a evolução do transporte rodoviário no Brasil. Monografia (Bacharelado) - Universidade Estadual Paulista, Araraquara, 2013.

LOENERT, F. M.. Como privatizar os Correios: uma oportunidade como ponte para a solução. MISES: Interdisciplinary Journal of Philosophy, Law and Economics, v.6, n.2, 2018.

MEDEIROS, H. G.. Análise das demonstrações contábeis: uma análise econômico-financeira da Empresa Brasileira de Correios e Telégrafos entre os anos de 2004 e 2013. Monografia (Bacharelado) - Universidade Federal do Rio Grande do Norte, Natal, 2014.

PEREIRA, V. A. F. F.. A desestatização no Brasil: uma análise acerca das privatizações. Monografia (Bacharelado) Universidade de Santa Cruz do Sul, Santa Cruz do Sul, 2019.

PINHEIRO, A. C.; GIAMBIAGI, F.. Os antecedentes macroeconômicos e a estrutura institucional da privatização do Brasil. In: PINHEIRO, A. C.; FUKASAKU, K.. A privatização no Brasil: o caso dos serviços de utilidade pública. Rio de Janeiro: Banco Nacional de Desenvolvimento Econômico e Social (BNDES), 2000. p.13-43.

ROEDEL, A. R.. A natureza jurídica da Empresa Brasileira de Correios e Telégrafos (ECT): uma empresa eficiente?.

Monografia (Bacharelado) - Universidade Federal de Santa Catarina, Florianópolis, 2019.

ROSA, M. B.. Uma análise das estratégias da Empresa Brasileira de Correios e Telégrafos para manter-se competitiva no mercado. Monografia (Especialização em 
Gestão Pública) - Universidade Federal de São João Del Rei, São João Del Rei, 2018

SILVA, S. A. L.. Desempenho de fundos de pensão sob a óptica das boas práticas de governança corporativa e da auditoria independente. Tese (Doutorado) - Universidade Federal de Minas Gerais, Belo Horizonte, 2018.

SILVA, G. H.. Monopólio postal: sua relevância e as transformações do sistema postal. Monografia (Especialização em Gestão Pública) - Universidade Federal de São João Del Rei, São João Del Rei, 2018.

TAVARES, M. R. N.. Estudos sobre as privatizações no Brasil na década de 1990. Monografia (Bacharelado) Universidade Federal do Tocantins, Palmas, 2019.
TEIXEIRA, T. G.. O sistema postal brasileiro em transformação: propostas e mudanças na regulação do mercado e na reestruturação do modelo organizacional da Empresa Brasileira de Correios e Telégrafos (1994-

2011). Rev. Adm. Pública, Rio de Janeiro, v.48, n.6, p.13551380. 2014. DOI: https://doi.org/10.1590/0034-76121470

TEIXEIRA, T. G.. Tendências do setor postal no cenário internacional: liberalização, regulação do mercado e reestruturação organizacional. Sociedade e Estado, v.31, n.2, p.349-372, 2016. DOI: https://doi.org/10.1590/003476121470

VENCESLAU, I.. Correios, logística e uso do território: o serviço de encomenda expressa no Brasil. Tese (Doutorado) Universidade de São Paulo, São Paulo, 2017.

A CBPC - Companhia Brasileira de Produção Científica (CNPJ: 11.221.422/0001-03) detém os direitos materiais desta publicação. Os direitos referem-se à publicação do trabalho em qualquer parte do mundo, incluindo os direitos às renovações, expansões e disseminações da contribuição, bem como outros direitos subsidiários. Todos os trabalhos publicados eletronicamente poderão posteriormente ser publicados em coletâneas impressas sob coordenação da Sustenere Publishing, da Companhia Brasileira de Produção Científica e seus parceiros autorizados. Os (as) autores (as) preservam os direitos autorais, mas não têm permissão para a publicação da contribuição em outro meio, impresso ou digital, em português ou em tradução. 